\title{
A phase II study of axitinib in advanced neuroendocrine tumors
}

\author{
J R Strosberg1, M Cives', J Hwang', T Weber², M Nickerson², C E Atreya2, \\ A Venook², R K Kelley², T Valone', B Morse', D Coppola' and E K Bergsland² \\ 'Department of Gastrointestinal Oncology, H. Lee Moffitt Cancer Center and Research Institute, Tampa, \\ Florida, USA \\ 2Department of Medicine and The UCSF Helen Diller Family Comprehensive Cancer Center, University of \\ California, San Francisco, California, USA
}

Correspondence should be addressed to J Strosberg

Email

jonathan.strosberg@ moffitt.org

\begin{abstract}
Neuroendocrine tumors (NETs) are highly vascular neoplasms overexpressing vascular endothelial growth factor (VEGF) as well as VEGF receptors (VEGFR). Axitinib is a potent, selective inhibitor of VEGFR-1, -2 and -3, currently approved for the treatment of advanced renal cell carcinoma. We performed an open-label, two-stage design, phase II trial of axitinib $5 \mathrm{mg}$ twice daily in patients with progressive unresectable/metastatic low-to-intermediate grade carcinoid tumors. The primary end points were progression-free survival (PFS) and 12-month PFS rate. The secondary end points included time to treatment failure (TTF), overall survival (OS), overall radiographic response rate (ORR), biochemical response rate and safety. A total of 30 patients were enrolled and assessable for toxicity; 22 patients were assessable for response. After a median follow-up of 29 months, we observed a median PFS of 26.7 months $(95 \% \mathrm{Cl}, 11.4-35.1)$, with a 12-month PFS rate of $74.5 \%( \pm 10.2)$. The median OS was 45.3 months ( $95 \% \mathrm{Cl}, 24.4-45.3)$, and the median TTF was 9.6 months ( $95 \% \mathrm{Cl}, 5.5-12)$. The best radiographic response was partial response (PR) in 1/30 (3\%) and stable disease (SD) in 21/30 patients (70\%); $8 / 30$ patients ( $27 \%$ ) were unevaluable due to early withdrawal due to toxicity. Hypertension was the most common toxicity that developed in 27 patients (90\%). Grade 3/4 hypertension was recorded in 19 patients $(63 \%)$, leading to treatment discontinuation in six patients $(20 \%)$. Although axitinib appears to have an inhibitory effect on tumor growth in patients with advanced, progressive carcinoid tumors, the high rate of grade 3/4 hypertension may represent a potential impediment to its use in unselected patients.
\end{abstract}

Key Words

- carcinoid tumor

- antiangiogenesis

- tyrosine kinase inhibitor

- VEGF

- VEGFR

\section{Introduction}

Neuroendocrine tumors (NETs) comprise a heterogeneous spectrum of malignancies characterized by a relatively indolent rate of growth and the ability to secrete a variety of hormones resulting in characteristic clinical syndromes, including carcinoid syndrome (Cives \& Strosberg 2014). NETs deriving from the enterochromaffin cells of the digestive tract and airways are often referred to as carcinoid tumors and are substantially different from pancreatic NETs (pNETs) in terms of biology and clinical behavior (Kulke et al. 2012).

Treatment options for metastatic carcinoid tumors have improved in recent years. Based on the results of the phase III PROMID and CLARINET trials (Rinke et al. 2009, Caplin et al. 2014), somatostatin analogs (SSAs) including octreotide and lanreotide have been formally incorporated into the clinical practice for patients

Published by Bioscientifica Ltd 
with gastroenteropancreatic NETs. More recently, the randomized phase III NETTER-1 trial evaluated peptide receptor radionuclide therapy (PRRT) vs octreotide $60 \mathrm{mg}$ long-acting repeatable (LAR) in patients with metastatic, progressive midgut NETs and demonstrated a $79 \%$ reduction in the risk for progression $(\mathrm{HR}=0.209$, $P<0.0001$ ) (Strosberg etal. 2015). Similarly, the RADIANT-4 trial randomized patients with advanced, progressive, nonfunctioning NETs of lung or gastrointestinal origin and showed a significant improvement in progression-free survival (PFS) from 3.9 months on placebo to 11 months with everolimus (Yao et al. 2016). However, even if everolimus and/or PRRT are approved for the treatment of carcinoid tumors, there will still be a clear need for additional systemic agents with antitumor activity.

NETs are highly vascularized neoplasms, and overexpression of vascular endothelial growth factor (VEGF) as well as VEGF receptor (VEGFR) subtypes has been reported, suggesting that autocrine activation of the VEGF pathway may play a critical role in tumor growth (La Rosa et al. 2003, Zhang et al. 2007, Besig et al. 2009). Thus far, trials on VEGF pathway inhibitors have demonstrated activity primarily in pNETs. A phase III trial of sunitinib in pNETs demonstrated significant improvement in PFS from 5.5 months on the control arm to 11.4 months in the experimental arm (Raymond et al. 2011), leading to its approval for this indication. The activity of VEGF pathway inhibitors such as the antiVEGF monoclonal antibody bevacizumab (Chan et al. 2012) and the VEGFR-targeted tyrosine kinase inhibitors (TKIs) - sunitinib (Kulke et al. 2008), sorafenib (Hobday et al. 2007) and pazopanib (Phan et al. 2015) - have been less convincing in carcinoid tumors, largely because phase II trials have been terminated on interim analysis due to lack of objective radiographic response. However, while the likelihood of radiographic response is low with angiogenesis inhibitors, improvement of survival durations appear to be very possible. As such, many believe that progression-free survival is a preferable end point for clinical trials with angiogenic inhibitors.

Axitinib is a TKI with picomolar potency against VEGFR-1, -2 and -3 (Hu-Lowe et al. 2008) and is approved for the second-line treatment of advanced renal cell carcinoma (RCC). When compared with sorafenib in patients with progressive RCC, axitinib resulted in significantly longer PFS $(\mathrm{HR}=0.665 ; P<0.0001)$, higher objective response rates (19\% vs $9 \% ; P=0.0001)$ and a favorable side effect profile (Rini et al. 2011).

We performed an open-label, single-arm, phase II study to assess the safety and efficacy of axitinib in patients with progressive, advanced, low-to-intermediate grade extra-pancreatic NETs. To test the hypothesis that potent and selective inhibition of VEGF pathway might result in prolonged disease stability, PFS and 1-year PFS rate were chosen as primary end points.

\section{Patients and methods}

\section{Patient selection}

This study was an open-label, single-arm, Simon twostage design, phase II prospective clinical trial funded by the National Comprehensive Cancer Network (NCCN). The protocol was approved by the Institutional Review Boards at each participating center. All patients provided written informed consent. The study was registered with clinicaltrials.gov (NCT01435122).

Subjects were adults (age $\geq 18 \mathrm{~s}$ ) with locally unresectable or metastatic grade 1 or 2 carcinoid tumors. Mitotic count and Ki-67 thresholds of $\leq 20$ for the tumor grade index were based on the World Health Organization (WHO) 2010 classification (Rindi \& Arnold 2010). Patients with poorly differentiated or high-grade tumors were excluded. Patients were required to have evidence of progressive disease within 12 months of study entry. Any number of prior systemic or locoregional treatments was allowed, and concurrent therapy with SSAs was permitted as long as patients remained on a stable dose. For patients with midgut NETs, prior SSA therapy was required for eligibility. Other key inclusion criteria were measurable disease by Response Evaluation Criteria in Solid Tumors (RECIST) (Eisenhauer et al. 2009), Eastern Cooperative Oncology Group (ECOG) performance status $\leq 2$, absolute neutrophil count $\geq 1500$ cells $/ \mu \mathrm{L}$, platelets $\geq 75,000$ cells $/ \mu \mathrm{L}$, total bilirubin $\leq 1.5$ times the upper limit of normal (ULN), AST and ALT $\leq 2.5$ times ULN ( $\leq 5$ times ULN if liver metastases were present), creatinine $\leq 1.5$ times ULN, PT and aPTT levels $\leq 1.5$ times ULN, and proteinuria $<2 \mathrm{~g} /$ day. Patients who had prior treatment with a dedicated VEGF pathway inhibitor, known brain metastases, a history of myocardial infarction, uncontrolled angina, congestive heart failure and cerebrovascular accident within 12 months from study entry, deep venous thrombosis, pulmonary embolism or hemorrhage within 6 months, as well as evidence of serious non-healing wound or ulcer, gastrointestinal perforation or bleeding, abdominal abscess or fistula, or uncontrolled thyroid dysfunction were excluded. Other key exclusion criteria included uncontrolled hypertension $(>140 / 90 \mathrm{mmHg})$ and use of CYP3A4 inhibitors and CYP3AR or CYP1A2 inducers.

Published by Bioscientifica Ltd. 


\section{Treatment and evaluation}

Axitinib was given orally with food at a dose of $5 \mathrm{mg}$ twice daily on a continuous 28-day cycle, until progressive disease (PD), unacceptable toxicity or withdrawal of consent. Patients were evaluated on day 1 of every cycle with physical examinations, vital signs including blood pressure, and routine blood tests. Patients experiencing hypertension (either systolic $\mathrm{BP}>140$ or diastolic $\mathrm{BP}>90$ ) were managed according to the investigator's judgment. Two dose reductions ( $3 \mathrm{mg}$ twice daily and then $2 \mathrm{mg}$ twice daily) were allowed for severe hypertension (>170/105 $\mathrm{mmHg}$ ) resistant to antihypertensive medications and other grade 3 or 4 drug-related toxicities. Patients who experienced recurrent severe hypertension or grade 3 or 4 toxicities after two dose reductions were excluded from the study. Toxicities were graded according to the National Cancer Institute (NCI) Common Terminology Criteria for Adverse Events (CTCAE) version 4.0. Evaluation visits were scheduled every 4 weeks along with standard blood and urine tests (complete blood count, comprehensive metabolic panel and urinalysis), whereas tumor markers such as chromogranin A (CgA) and 5-hydroxyindoleacetic acid (5-HIAA) were measured every 12 weeks, if elevated at baseline. Radiological assessment was performed by local radiologists who were blinded to patient clinical characteristics every 12 weeks using CT or MRI scans. The RECIST version 1.1 (Eisenhauer et al. 2009) was used for the evaluation of tumor response.

\section{Sample size calculation}

The primary efficacy end points were progression-free survival (PFS) and 12-month PFS rate. Secondary end points included time to treatment failure (TTF), overall survival (OS), overall radiographic response rate (ORR), biochemical response rate and adverse events. The sample size calculation was based on the assumption that a true 12 -month PFS rate of $>56.5 \%$ would be necessary to consider the investigational treatment sufficiently active to pursue in further studies, whereas a true 12-month PFS rate of $<36 \%$ would not yield further interest in this agent. These PFS rates correspond to null and alternative hypothesis - median PFS 8.1 and 14.6 months, respectively. The sample size was chosen based on a one-sided $\alpha$ level of $10 \%$ and a power of $80 \%$, assuming an exponential PFS distribution.

According to a Simon two-stage design (Simon 1989), the trial was monitored for early stopping. The interim analysis for futility was conducted when 18 patients were enrolled and followed up for 6 months. If $\geq 8 \mathrm{PD}$ were observed, the trial was to be terminated. When 15 patients completed two cycles of therapy, the trial was also monitored for safety. If there were $\leq 3$ grade 3 or higher toxicities (with the exception of hypertension), an additional 15 patients could be enrolled for the second stage.

\section{Statistical analysis}

The Kaplan-Meier method was used to estimate all timeto-event functions. PFS was calculated from the date of first study treatment until the date of first progressive disease or death due to any cause. OS was defined as the time from the initiation of treatment until death due to any cause, with patients censored at the date of last follow-up if still alive. TTF was defined as the time from administration of the initial dose of axitinib until study discontinuation for any reason. Exact 95\% confidence intervals (CIs) were calculated for each proportion of interest. All tests were two sided and statistical significance was declared at $P<0.05$. Statistical analysis was performed using MedCalc statistical software 12.7 (MedCalc Software bvba, Ostend, Belgium).

\section{Results}

\section{Patient population}

Demographic variables and clinical characteristics of 30 patients enrolled in the study are listed in Table 1. The median age of the patient population was 64 (35-77) s. The majority (29/30) of them had a performance status of 0 or 1 , and more than two thirds (21/30) had grade 1 tumors. Primary tumor sites included small intestine (19 patients), lung $(n=3)$, colon and rectum $(n=4)$, thymus $(n=1)$, and unknown $(n=3)$. Of the total patients, 18 had hormonally functioning tumors, including 16 patients with carcinoid syndrome, one patient with gastrin-producing tumor and one patient with ectopic ACTH secretion. The primary tumor had been resected in 22/30 patients before enrollment on the trial. Most patients $(21 / 30)$ had received only one prior line of systemic therapy; 27 received prior octreotide LAR, four received prior cytotoxic chemotherapy (including etoposide/cisplatin and capecitabine/ temozolomide), three had prior everolimus, three had prior interferon- $\alpha$, one had prior PRRT, and five had prior investigational agents (including pasireotide, erlotinib and ganitumab). At study entry, 25/30 patients remained on octreotide $\mathrm{LAR}$.

Published by Bioscientifica Ltd. 
Table 1 Baseline characteristics of the study population.

\begin{tabular}{|c|c|c|}
\hline Characteristics & Patients $(n=30)$ & $\%$ \\
\hline \multicolumn{3}{|l|}{ Age (years) } \\
\hline Median & 64 & \\
\hline Range & $35-77$ & \\
\hline \multicolumn{3}{|l|}{ Gender } \\
\hline Male & 13 & 43 \\
\hline Female & 17 & 57 \\
\hline \multicolumn{3}{|l|}{ Race } \\
\hline White & 27 & 91 \\
\hline Black & 1 & 3 \\
\hline Asian & 1 & 3 \\
\hline Unknown & 1 & 3 \\
\hline \multicolumn{3}{|c|}{ Performance status (ECOG) } \\
\hline 0 & 20 & 67 \\
\hline 1 & 9 & 30 \\
\hline 2 & 1 & 3 \\
\hline \multicolumn{3}{|c|}{ Time from diagnosis (months) } \\
\hline Median & 38 & \\
\hline Range & $2-171$ & \\
\hline \multicolumn{3}{|l|}{ Tumor grade } \\
\hline Grade 1 & 21 & 70 \\
\hline Grade 2 & 9 & 30 \\
\hline \multicolumn{3}{|c|}{ Location of primary tumor } \\
\hline Small intestine & 19 & 63 \\
\hline Lung & 3 & 10 \\
\hline Colon & 2 & 7 \\
\hline Rectum & 2 & 7 \\
\hline Thymus & 1 & 3 \\
\hline Unknown & 3 & 10 \\
\hline \multicolumn{3}{|c|}{ History of carcinoid syndrome } \\
\hline Yes & 16 & 53 \\
\hline No & 14 & 47 \\
\hline \multicolumn{3}{|c|}{$\begin{array}{l}\text { Elevated baseline chromogranin A } \\
\quad(>\text { ULN) }\end{array}$} \\
\hline Yes & 25 & 84 \\
\hline No & 4 & 13 \\
\hline Unknown & 1 & 3 \\
\hline \multicolumn{3}{|c|}{$\begin{array}{l}\text { Baseline chromogranin } \mathrm{A}(\mathrm{nL}<15 \\
\mathrm{ng} / \mathrm{mL})\end{array}$} \\
\hline Median & 90 & \\
\hline Mean & 597 & \\
\hline Range & $2-9200$ & \\
\hline \multicolumn{3}{|c|}{ Elevated baseline 5-HIAA } \\
\hline Yes & 18 & 60 \\
\hline No & 8 & 27 \\
\hline Unknown & 4 & 13 \\
\hline \multicolumn{3}{|c|}{ Primary tumor resected } \\
\hline Yes & 22 & 73 \\
\hline No & 8 & 27 \\
\hline \multicolumn{3}{|l|}{ Liver involvement } \\
\hline 0 & 2 & 6 \\
\hline$<10$ & 11 & 37 \\
\hline$\geq 10$ & 17 & 57 \\
\hline \multicolumn{3}{|c|}{ Previous liver-directed therapy } \\
\hline Yes & 11 & 37 \\
\hline No & 19 & 63 \\
\hline \multicolumn{3}{|c|}{ Concurrent octreotide LAR } \\
\hline Yes & 25 & 83 \\
\hline No & 5 & 17 \\
\hline
\end{tabular}

(Continued)

http://erc.endocrinology-journals.org DOI: 10.1530/ERC-16-0008
Table 1 (Continued)

\begin{tabular}{|c|c|c|}
\hline Characteristics & Patients $(n=30)$ & $\%$ \\
\hline \multicolumn{3}{|c|}{ Prior lines of systemic therapy } \\
\hline Median & 1 & \\
\hline Range & $1-3$ & \\
\hline \multicolumn{3}{|l|}{ Previous systemic therapy } \\
\hline Octreotide LAR & 27 & 90 \\
\hline Chemotherapy & 4 & 13 \\
\hline Everolimus & 3 & 10 \\
\hline Interferon- $\alpha$ & 3 & 10 \\
\hline PRRT & 1 & 3 \\
\hline Investigational agents & 5 & 17 \\
\hline
\end{tabular}

\section{Duration of therapy}

At the interim analysis, we recorded two $\mathrm{PD}$ and two grade $3 / 4$ toxicities. Thus, the null hypothesis that treatment was futile and toxic was rejected, and we continued accrual to 30 patients in total as per protocol. Patients received a median of nine 28-day treatment cycles. Of the 30 patients, 12 (40\%) had at least one dosing interruption and eight patients (27\%) required at least a single-dose reduction. Of the 30 patients who began treatment, 22 received more than three cycles. The median TTF was 9.6 months (95\% CI, 5.5-12 months). Reasons for discontinuation included radiographic tumor progression $(n=10)$, unacceptable toxicity $(n=13)$, symptomatic decline $(n=5)$ and physician decision $(n=1)$. One patient remained on drug at the time of data analysis. Toxicities leading to treatment discontinuation included uncontrolled hypertension $(n=6)$, fatigue $(n=3)$, abdominal pain $(n=2)$, hand-foot syndrome $(n=1)$ and hyperbilirubinemia $(n=1)$.

\section{Progression-free and overall survival}

All enrolled patients were evaluable for PFS, OS and TTF. At the time of data cutoff, nine patients had died and 21 were alive, with median follow-up of 29 months (range 1-45.3 months). As depicted in Fig. 1A, the median overall PFS was 26.7 months (95\% CI, 11.4-35.1), and the 12 -month PFS rate was $74.5 \%( \pm 10.2)$. Stratified by tumor group, the median PFS of patients with small bowel carcinoids and NETs of other primary sites was 28 months (95\% CI, 11.4-35.1 months) and 25.1 months (95\% CI, 14.4-26.7 months), respectively $(P=0.99)$. By grade, the median PFS of patients with grade 1 and 2 tumors was 28 months (95\% CI, 25.1-35.1 months) and 14.4 months (95\% CI, 8.5-26.7 months; $P=0.26$ ), respectively. There was no difference in PFS between

Published by Bioscientifica Ltd 
A
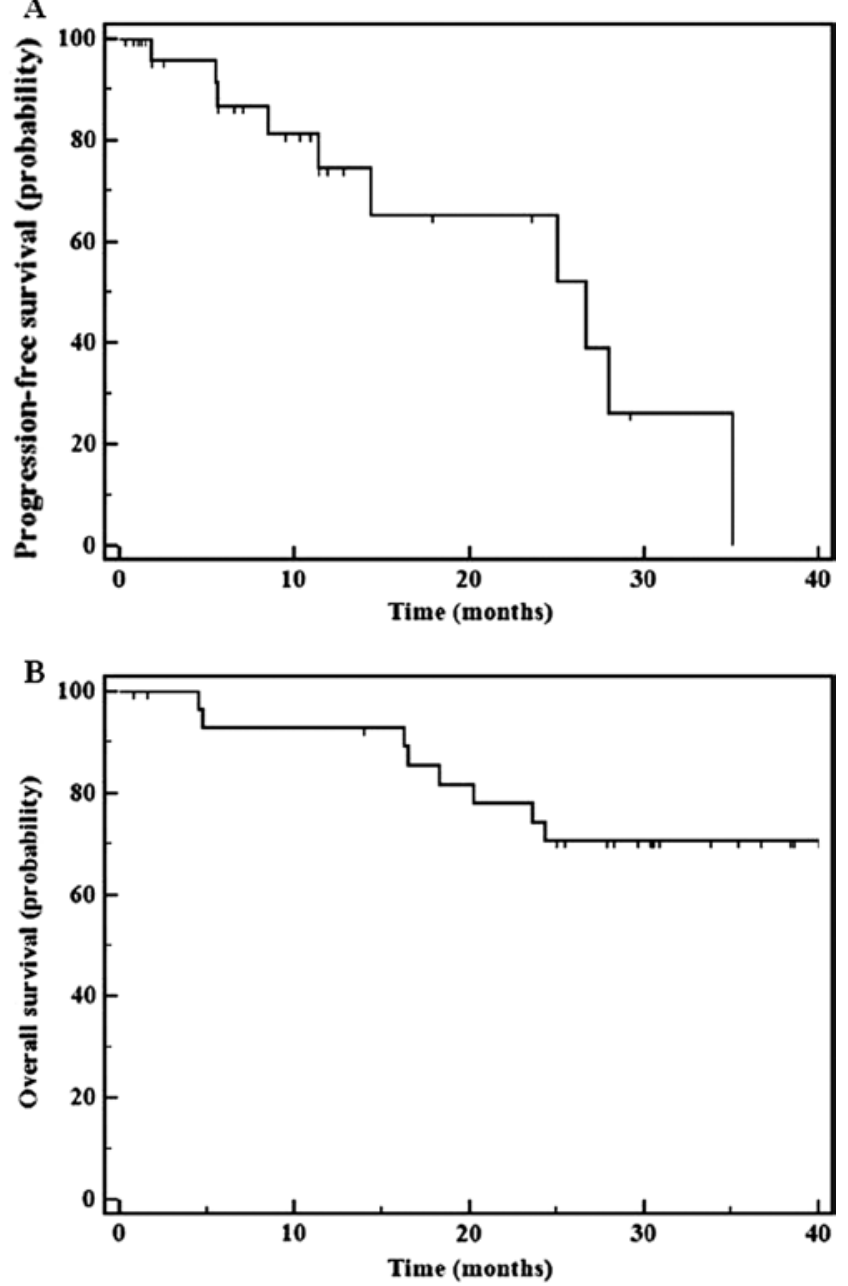

Figure 1

Kaplan-Meier estimates of progression-free survival (A) and overall survival (B).

patients with high $(\geq 10 \%)$ and low $(<10 \%)$ hepatic tumor burden $(P=0.64)$.

The median OS was 45.3 months (95\% CI, 24.4-45.3 months; Fig. 1B). The 12- and 24-month OS rates were $93 \%( \pm 4.9 \%)$ and $74.3 \%( \pm 8.4 \%)$, respectively.

\section{Radiological and biochemical response}

Among 30 enrolled patients, 22 were evaluable for response. The remaining eight patients (27\%) withdrew from the study before radiographic evaluation due to toxicity (hypertension, $n=6$; fatigue $n=2$ ). When the best response to therapy was evaluated, 3\% (1/30) patients partially responded according to RECIST criteria, whereas $70 \%(21 / 30)$ had stable disease, including an unconfirmed partial response. The waterfall plot analysis showed some

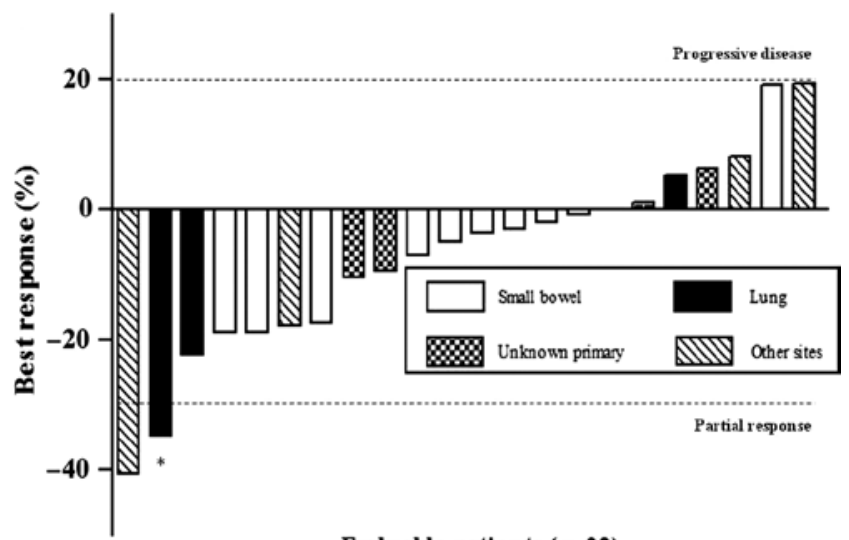

Evaluable patients $(n=22)$

Figure 2

Waterfall plot illustrating best radiographic response (\% change) in each enrolled patient. *Decrease not confirmed at subsequent radiographic assessment, thus failing to match RECIST criteria for partial response.

degree of tumor shrinkage in 68\% (15/22) of evaluable patients and no change or continued tumor growth in $32 \%(7 / 22)$ of the cohort. Figure 2 summarizes the maximum percent change from baseline in the sum of the longest diameters of target lesions.

Among 18 patients with baseline elevated (>ULN) serum CgA levels and at least one repeat measurement, four patients (22\%) experienced major reduction (>50\%) or normalization of the tumor marker. Eighteen patients had baseline elevations (>ULN) of 5-HIAA, and repeat measurements were available in 11 patients. Major 5-HIAA responses were recorded in 5/11 evaluable patients (45\%). Differences between the median baseline CgA and 5-HIAA concentration and their lowest value following initiation of treatment were statistically significant $(P=0.04$ and $P=0.01$, respectively; Fig. $3 \mathrm{~A}$ and $\mathrm{B})$. As we identified only one objective response in our cohort, no reliable associations between biochemical response and likelihood of radiographic response could be made. Exploratory analysis of PFS and OS did not reveal an association with either CgA or 5-HIAA response.

\section{Safety}

All the study patients were evaluated for toxicity. The side effects considered at least possibly related to the treatment are listed in Table 2. Hypertension was the most common toxicity and developed in 27 patients (90\%), requiring intervention in 21 individuals (70\%). In 19 patients (63\%), hypertension was of grade $3 / 4$. No carcinoid crisis episodes were observed. Other common adverse events included fatigue (60\%), headache (47\%), diarrhea (33\%),

Published by Bioscientifica Ltd 
A

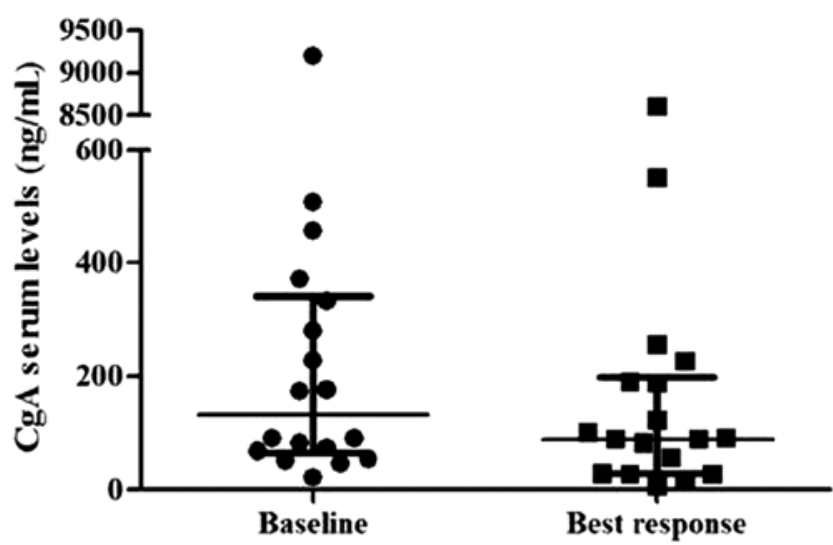

B

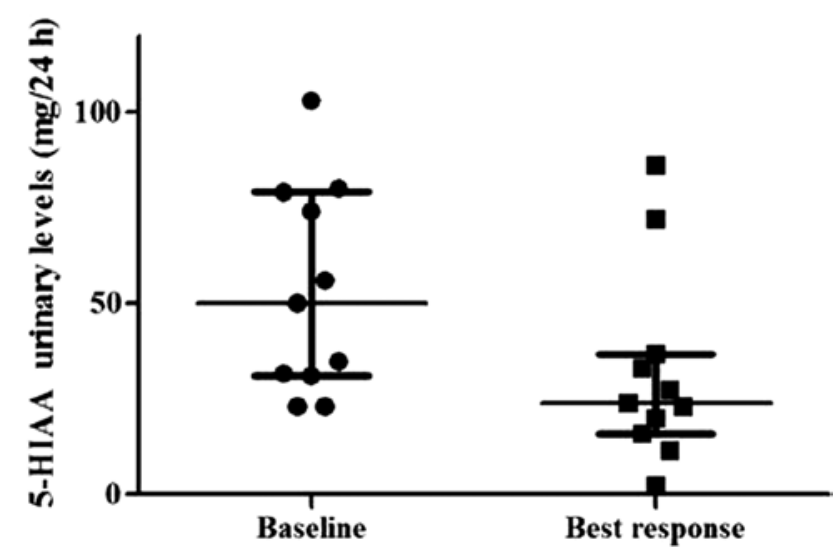

Figure 3

Biochemical response following axitinib treatment. (A) In patients with elevated baseline $\mathrm{CgA}$ and repeat measurements, median $\mathrm{CgA}$ concentrations decreased from 132 to $89 \mathrm{ng} / \mathrm{mL}$. The decrease was statistically significant $(P=0.04)$ by Wilcoxon matched pairs signed-rank test. (B) Median urinary levels of 5 -HIAA decreased from $50 \mathrm{mg} / 24 \mathrm{~h}$ at baseline to $24 \mathrm{mg} / 24 \mathrm{~h}$ when best response was evaluated $(P=0.01)$. Paired row values, median change and interquartile range are represented.

nausea (30\%), vomiting (20\%), weight loss (23\%), anorexia (20\%), hoarseness (30\%) and thrombocytopenia (23\%). The only observed grade 4 toxicity was hypertensive emergency associated with radiographic evidence of mild intracranial hemorrhage (3\%). The patient recovered fully from this event. No treatment-related death was reported.

\section{Discussion}

This study suggests that axitinib has antitumor activity in patients with advanced, progressive carcinoid tumors, but is associated with a high rate (90\%) of hypertension and other toxicities leading to study discontinuation for
Table 2 Grade 2 and higher toxicities considered at least possibly related to treatment.

\begin{tabular}{|c|c|c|c|c|}
\hline & Grade 2 & Grade 3 & Grade 4 & Total \\
\hline Hypertension (\%) & $7(23)$ & $17(57)$ & $2(7)$ & $26(87)$ \\
\hline \multicolumn{5}{|c|}{ Gastrointestinal toxicity (\%) } \\
\hline Abdominal pain & $4(14)$ & $1(3)$ & $0(0)$ & $5(17)$ \\
\hline Diarrhea & $4(14)$ & $1(3)$ & $0(0)$ & $5(17)$ \\
\hline Nausea & $3(10)$ & $1(3)$ & $0(0)$ & $4(13)$ \\
\hline Vomiting & $2(7)$ & $0(0)$ & $0(0)$ & $2(7)$ \\
\hline Mucositis & $1(3)$ & $0(0)$ & $0(0)$ & $1(3)$ \\
\hline Oral pain & $1(3)$ & $0(0)$ & $0(0)$ & $1(3)$ \\
\hline \multicolumn{5}{|c|}{ Neurologic toxicity (\%) } \\
\hline Headache & $4(13)$ & $2(7)$ & $0(0)$ & $6(20)$ \\
\hline Confusion & $0(0)$ & $1(3)$ & $0(0)$ & $1(3)$ \\
\hline Insomnia & $0(0)$ & $1(3)$ & $0(0)$ & $1(3)$ \\
\hline Syncope & $0(0)$ & $1(3)$ & $0(0)$ & $1(3)$ \\
\hline Anxiety & $1(3)$ & $0(0)$ & $0(0)$ & $1(3)$ \\
\hline $\begin{array}{l}\text { Intracranial } \\
\text { hemorrhage }\end{array}$ & $0(0)$ & $0(0)$ & $1(3)$ & $1(3)$ \\
\hline \multicolumn{5}{|l|}{ Miscellaneous (\%) } \\
\hline Fatigue & $6(20)$ & $2(7)$ & $0(0)$ & $8(27)$ \\
\hline Weight loss & 1 (3) & $1(3)$ & $0(0)$ & $2(6)$ \\
\hline Anorexia & $1(3)$ & $0(0)$ & $0(0)$ & $1(3)$ \\
\hline Myalgia & $0(0)$ & $1(3)$ & $0(0)$ & $1(3)$ \\
\hline Dehydration & $2(7)$ & $1(3)$ & $0(0)$ & $3(10)$ \\
\hline Hypothyroidism & $1(3)$ & $0(0)$ & $0(0)$ & $1(3)$ \\
\hline $\begin{array}{l}\text { Increased } \\
\text { transaminases }\end{array}$ & $1(3)$ & $0(0)$ & $0(0)$ & $1(3)$ \\
\hline $\begin{array}{l}\text { Increased alkaline } \\
\text { phosphatase }\end{array}$ & $3(10)$ & $0(0)$ & $0(0)$ & $3(10)$ \\
\hline $\begin{array}{l}\text { Increased gamma- } \\
\text { glutamyl } \\
\text { transferase }\end{array}$ & $0(0)$ & $1(3)$ & $0(0)$ & $1(3)$ \\
\hline $\begin{array}{l}\text { Urinary tract } \\
\text { infection }\end{array}$ & $1(3)$ & $0(0)$ & $0(0)$ & $1(3)$ \\
\hline $\begin{array}{l}\text { Right ventricular } \\
\text { dysfunction }\end{array}$ & $0(0)$ & $1(3)$ & $0(0)$ & $1(3)$ \\
\hline Pain in extremity & $1(3)$ & $0(0)$ & $0(0)$ & $1(3)$ \\
\hline Hand-foot syndrome & $0(0)$ & $1(3)$ & $0(0)$ & $1(3)$ \\
\hline
\end{tabular}

reasons other than disease progression in a significant number of subjects.

Antiangiogenic agents have an established place in the medical treatment of patients with NETs, and sunitinib is approved for pNETs based on the results of a phase III trial (Raymond et al. 2011). In carcinoid tumors, TKIs including sunitinib (Kulke et al. 2008), sorafenib (Hobday et al. 2007) and pazopanib (Phan et al. 2015) have shown thus far only marginal activity in terms of tumor shrinkage. However, objective response might not be the optimum end point for nonrandomized carcinoid trials, and delay in progression in the absence of radiographically defined tumor response can be expected during treatment with cytostatic agents (Kulke et al. 2011).

In this trial, we assumed that median PFS in the absence of treatment would be 8.1 months, whereas a median study PFS of at least 14.6 months would indicate

Published by Bioscientifica Ltd 
that axitinib had antitumor activity. These assumptions were generated according to previous clinical trials conducted in a similar population of patients with advanced, progressive extra-pancreatic NETs, including the placebo plus octreotide LAR arm of the RADIANT-2 trial (Pavel et al. 2011) (median PFS 8.6 months by local investigator assessment; $71 \%$ of these patients had received prior SSA therapy). Comparison with local rather than central review was justified by the lack of central adjudication in our study. We observed a median PFS of 26.7 months (95\% CI, 11.4-35.1), with a 12-month PFS rate of $74.5 \%( \pm 10.2)$. Although cross-trial comparisons should be drawn with caution, these results compare favorably with reported results for other antiangiogenic TKIs. In fact, in a phase II study of sunitinib, the median time to progression (TTP) was 10.2 months (95\% CI, 9.2-17.5) in the carcinoid tumor cohort, although progressive disease was not necessary for enrollment (Kulke et al. 2008). Similarly, 6-month PFS rate was $40 \%$ in patients with carcinoids who received sorafenib (Hobday et al. 2007), and pazopanib was associated with a median PFS of 8.4 months (95\% CI, 0-16.9) in carcinoid patients with progressive disease at enrollment (Phan et al. 2015). The median PFS recorded in this study also compares favorably with a median investigator-assessed PFS of 14 months (95\% CI, 11.2-17.7) recently reported for everolimus, an agent deemed active in progressive, extra-pancreatic NETs (Yao et al. 2016).

However, our results are limited by a relatively high rate of patient withdrawal before progression due to toxicity. This explains the wide CIs surrounding the median PFS and the discrepancy with the observed median TTF of 9.6 months ( $95 \% \mathrm{CI}, 5.5-12$ months). The relatively high rates of hypertension and fatigue raise concerns about the tolerability of axitinib in a certain subset of carcinoid patients. Toxicities associated with axitinib were largely consistent with the known side effect profile of TKIs targeting the VEGF/VEGFR axis. However, we observed an unexpectedly high rate (90\%) of elevated blood pressure, with grade $3 / 4$ hypertension arising in $64 \%$ of the patients. These rates were substantially higher than those reported with the same agent for other cancers, including renal cell carcinoma and pancreatic adenocarcinoma (Kindler et al. 2011, Rini et al. 2011, Qi et al. 2013). The expected rate of grade $3 / 4$ hypertension is approximately $15 \%$ in patients with renal cell carcinoma (Rini et al. 2011, Hutson et al. 2013). The significance of the high rate of hypertension in this study is unclear, but may reflect confounding factors unique to carcinoid.
Concurrent secretion of vasoactive neuropeptides has been hypothesized as possibly related to the increased risk of hypertension in patients with carcinoid tumors following treatment with antiangiogenic TKIs (Kulke et al. 2008). In our study, all patients $(n=6)$ who discontinued axitinib because of uncontrolled hypertension had carcinoid syndrome. Importantly, in this study the frequency and severity of hypertension were also higher than in carcinoid patients treated with bevacizumab (Yao et al. 2015), sunitinib (Kulke et al. 2008) or pazopanib (Phan et al. 2015). A deeper understanding of the underlying pathogenesis and potential risk factors contributing to hypertension development in NET patients treated with axitinib is needed, in order to maximize the risk:benefit ratio associated with the drug. It is conceivable that the dose, schedule and/or dose modification scheme could be further optimized so as to limit toxicity while preserving efficacy. The predictive value of hypertension in patients treated with antiangiogenic agents is uncertain and may depend on the relative role of angiogenesis and the specific disease type (Dienstmann et al. 2011).

\section{Conclusion}

Axitinib appears to have an inhibitory effect on tumor growth in patients with advanced, progressive carcinoid tumors. However, the high rate of grade $3 / 4$ hypertension may represent a potential impediment to the use of standard dose axitinib in unselected patients. If future studies of axitinib are initiated in this disease, monitoring and earlier and more aggressive management of blood pressure upon initiation of treatment need to be incorporated into the study design. Examination of additional dose levels and/or schedules may also be fruitful, recognizing that patients with carcinoid syndrome appear to be at particularly high risk for hypertension.

\section{Declaration of interest}

Dr Strosberg has performed consultation for Novartis, Ipsen and Lexicon within institutional conflict of interest payment guidelines. Dr Bergsland has served as a consultant for Ipsen (payment to institution), Novartis (uncompensated) and Lexicon (uncompensated). All the remaining authors have declared no conflicts of interest.

\section{Funding}

This study was approved and funded by the National Comprehensive Cancer Network (NCCN) Oncology Research Program from the general research support provided by Pfizer, Inc. 


\section{References}

Besig S, Voland P, Baur DM, Perren A \& Prinz C 2009 Vascular endothelial growth factors, angiogenesis, and survival in human ileal enterochromaffin cell carcinoids. Neuroendocrinology 90 402-415. (doi:10.1159/000245900)

Caplin ME, Pavel M, Ćwikła JB, Phan AT, Raderer M, Sedláčková E, Cadiot G, Wolin EM, Capdevila J, Wall L, et al. 2014 Lanreotide in metastatic enteropancreatic neuroendocrine tumors. New England Journal of Medicine 371 224-233. (doi:10.1056/NEJMoa1316158)

Chan JA, Stuart K, Earle CC, Clark JW, Bhargava P, Miksad R, Blaszkowsky L, Enzinger PC, Meyerhardt JA, Zheng H, et al. 2012 Prospective study of bevacizumab plus temozolomide in patients with advanced neuroendocrine tumors. Journal of Clinical Oncology 30 2963-2968. (doi:10.1200/JCO.2011.40.3147)

Cives M \& Strosberg J 2014 An update on gastroenteropancreatic neuroendocrine tumors. Oncology 28 749-756.

Dienstmann R, Braña I, Rodon J \& Tabernero J 2011 Toxicity as a biomarker of efficacy of molecular targeted therapies: focus on EGFR and VEGF inhibiting anticancer drugs. Oncologist 16 1729-1740. (doi:10.1634/theoncologist.2011-0163)

Eisenhauer EA, Therasse P, Bogaerts J, Schwartz LH, Sargent D, Ford R, Dancey J, Arbuck S, Gwyther S, Mooney M, et al. 2009 New response evaluation criteria in solid tumours: revised RECIST guideline (version 1.1). European Journal of Cancer 45 228-247. (doi:10.1016/ j.ejca.2008.10.026)

Hobday TJ, Rubin J, Holen K, Picus J, Donehower R, Marschke R, Maples W, Lloyd R, Mahoney M \& Erlichman C 2007 MC044 h, a phase II trial of sorafenib in patients (pts) with metastatic neuroendocrine tumors (NET): a Phase II Consortium (P2C) study. (ASCO Annual Meeting Proceedings Part I). Journal of Clinical Oncology 25 S4504.

Hu-Lowe DD, Zou HY, Grazzini ML, Hallin ME, Wickman GR, Amundson K, Chen JH, Rewolinski DA, Yamazaki S, Wu EY, et al. 2008 Nonclinical antiangiogenesis and antitumor activities of axitinib (AG-013736), an oral, potent, and selective inhibitor of vascular endothelial growth factor receptor tyrosine kinases 1, 2, 3. Clinical Cancer Research 14 7272-7283. (doi:10.1158/1078-0432.CCR-08-0652)

Hutson TE, Lesovoy V, Al-Shukri S, Stus VP, Lipatov ON, Bair AH, Rosbrook B, Chen C, Kim S \& Vogelzang NJ 2013 Axitinib versus sorafenib as first-line therapy in patients with metastatic renal-cell carcinoma: a randomised open-label phase 3 trial. Lancet Oncology 14 1287-1294. (doi:10.1016/S1470-2045(13)70465-0)

Kindler HL, Ioka T, Richel DJ, Bennouna J, Létourneau R, Okusaka T, Funakoshi A, Furuse J, Park YS, Ohkawa S, et al. 2011 Axitinib plus gemcitabine versus placebo plus gemcitabine in patients with advanced pancreatic adenocarcinoma: a double-blind randomised phase 3 study. Lancet Oncology 12 256-262. (doi:10.1016/S1470-2045(11)70004-3)

Kulke MH, Lenz HJ, Meropol NJ, Posey J, Ryan DP, Picus J, Bergsland E, Stuart K, Tye L, Huang X, et al. 2008 Activity of sunitinib in patients with advanced neuroendocrine tumors. Journal of Clinical Oncology 26 3403-3410. (doi:10.1200/JCO.2007.15.9020)

Kulke MH, Siu LL, Tepper JE, Fisher G, Jaffe D, Haller DG, Ellis LM, Benedetti JK, Bergsland EK, Hobday TJ, et al. 2011 Future directions in the treatment of neuroendocrine tumors: consensus report of the National Cancer Institute Neuroendocrine Tumor clinical trials planning meeting. Journal of Clinical Oncology 29 934-943. (doi:10.1200/JCO.2010.33.2056)

Kulke MH, Benson AB 3rd, Bergsland E, Berlin JD, Blaszkowsky LS, Choti MA, Clark OH, Doherty GM, Eason J, Emerson L, et al. 2012 Neuroendocrine tumors. Journal of the National Comprehensive Cancer Network 10 724-764.

La Rosa S, Uccella S, Finzi G, Albarello L, Sessa F \& Capella C 2003 Localization of vascular endothelial growth factor and its receptors in digestive endocrine tumors: correlation with microvessel density and clinicopathologic features. Human Pathology 34 18-27. (doi:10.1053/hupa.2003.56)

Pavel ME, Hainsworth JD, Baudin E, Peeters M, Hörsch D, Winkler RE, Klimovsky J, Lebwohl D, Jehl V, Wolin EM, et al. 2011 Everolimus plus octreotide long-acting repeatable for the treatment of advanced neuroendocrine tumours associated with carcinoid syndrome (RADIANT-2): a randomised, placebo-controlled, phase 3 study. Lancet 378 2005-2012. (doi:10.1016/S0140-6736(11)61742-X)

Phan AT, Halperin DM, Chan JA, Fogelman DR, Hess KR, Malinowski P, Regan E, Ng CS, Yao JC \& Kulke MH 2015 Pazopanib and depot octreotide in advanced, well-differentiated neuroendocrine tumours: a multicentre, single-group, phase 2 study. Lancet Oncology 16 695-703. (doi:10.1016/S1470-2045(15)70136-1)

Qi WX, He AN, Shen Z \& Yao Y 2013 Incidence and risk of hypertension with a novel multi-targeted kinase inhibitor axitinib in cancer patients: a systematic review and meta-analysis. British Journal of Clinical Pharmacology 76 348-357. (doi:10.1111/bcp.12149)

Raymond E, Dahan L, Raoul JL, Bang YJ, Borbath I, Lombard-Bohas C, Valle J, Metrakos P, Smith D, Vinik A, et al. 2011 Sunitinib malate for the treatment of pancreatic neuroendocrine tumors. New England Journal of Medicine 364 501-513. (doi:10.1056/NEJMoa1003825)

Rindi G \& Arnold R 2010 Nomenclature and classification of neuroendocrine neoplasms of the digestive system. In World Health Organization Classification of Tumours of the Digestive System, pp 13-14. Eds F Bosman, F Carneiro, R Hruban \& N Theise. Lyon, France: IARC Press.

Rini BI, Escudier B, Tomczak P, Kaprin A, Szczylik C, Hutson TE, Michaelson MD, Gorbunova VA, Gore ME, Rusakov IG, et al. 2011 Comparative effectiveness of axitinib versus sorafenib in advanced renal cell carcinoma (AXIS): a randomised phase 3 trial. Lancet 378 1931-1939. (doi:10.1016/S0140-6736(11)61613-9)

Rinke A, Müller HH, Schade-Brittinger C, Klose KJ, Barth P, Wied M, Mayer C, Aminossadati B, Pape UF, Bläker M, et al. 2009 Placebocontrolled, double-blind, prospective, randomized study on the effect of octreotide LAR in the control of tumor growth in patients with metastatic neuroendocrine midgut tumors: a report from the PROMID Study Group. Journal of Clinical Oncology 27 4656-4663. (doi:10.1200/JCO.2009.22.8510)

Simon R 1989 Optimal two-stage designs for phase II clinical trials. Controlled Clinical Trials 10 1-10. (doi:10.1016/0197-2456(89)90015-9)

Strosberg J, Wolin E, Chasen B, Kulke M, Bushnell D, Caplin M, Baum RP, Mittra E, Hobday T, Hendifar A, et al. 2015 6LBA 177-Lu-Dotatate significantly improves progression-free survival in patients with midgut neuroendocrine tumours: results of the phase III NETTER-1 trial. European Journal of Cancer $\mathbf{5 1}$ S710.

Yao JC, Guthrie K, Moran C, Strosberg JR, Kulke MH, Chan JA, LoConte NK, McWilliams RR, Wolin EM, Mattar BI, et al. 2015 SWOG S0518: Phase III prospective randomized comparison of depot octreotide plus interferon alpha- $2 \mathrm{~b}$ versus depot octreotide plus bevacizumab (NSC \#704865) in advanced, poor prognosis carcinoid patients (NCT00569127). Journal of Clinical Oncology 33 4004.

Yao JC, Fazio N, Singh S, Buzzoni R, Carnaghi C, Wolin E, Tomasek J, Raderer M, Lahner H, Voi M, et al. 2016 Everolimus for the treatment of advanced, non-functional neuroendocrine tumours of the lung or gastrointestinal tract (RADIANT-4): a randomised, placebo-controlled, phase 3 study. Lancet 387 968-977. (doi:10.1016/ S0140-6736(15)00817-X)

Zhang J, Jia Z, Li Q, Wang L, Rashid A, Zhu Z, Evans DB, Vauthey JN, Xie K \& Yao JC. 2007 Elevated expression of vascular endothelial growth factor correlates with increased angiogenesis and decreased progressionfree survival among patients with low-grade neuroendocrine tumors. Cancer 109 1478-1486. (doi:10.1002/cncr.22554)

Received in final form 22 March 2016

Accepted 13 April 2016

Accepted Preprint published online 14 April 2016

Published by Bioscientifica Ltd. http://erc.endocrinology-journals.org

DOI: 10.1530/ERC-16-0008
(C) 2016 Society for Endocrinology Printed in Great Britain 